Canadian Journal of Family and Youth, 6(1), 2014, pp 115-133

ISSN 1718-9748 () University of Alberta

http://ejournals.library.ualberta.ca/index/php/cjfy

\title{
Parental Mental Illness and Coping: An Exploratory Survey
}

\author{
Lisa Baker and Rob Lees
}

\begin{abstract}
The prevalence of Mental Health Concerns (MHC) among parents whose children are accessing services from a mental health outpatient center was explored, along with what helps and hinders the coping of those parents identified as having diagnosed or suspected MHC. Participants were selected based on interviews with their child's mental health clinician who identified $71 \%$ of the selected families as having at least one parent with diagnosed or suspected MHC. Semistructured phone interviews with 28 participants in those families were then conducted. Given the diversity and problem with language depicting mental illness, MHC was the rubric adopted for this paper as it was believed to be less of a problematic label. A qualitative research design provided a deeper understanding into the resources that parents utilize to help them cope, the challenges that make it more difficult for them to do well, and the supports they wish they had. There was a high correlation between clinician perception and participant self-report in indicating the presence of MHC. Resources revealed as helpful to parent coping included the assistance of counselling and medical professionals, community and family supports, and medication. Hindrances to parent coping included lack of finances, parenting stress, and difficulties related to MHC. Parents wished there were more services and supports available across professional and community domains. Findings may provide insight for family centered, integrative program ideas and supports that will increase family coping when both parents and children are dealing with MHC.
\end{abstract}

Lisa Baker, MA is a Registered Clinical Counsellor who has worked as a mental health clinician with Child and Youth Mental Health for the past three years. Email address: Lisa.E.Baker@gov.bc.ca Dr. Rob Lees (Ed. D) has been involved with Children of Parents with a Mental Illness (COPMI) issues for 16 years, having led the BC Provincial Committee on Supporting Families with Parental Mental Illness. He is a registered psychologist having earned his doctorate at the University of British Columbia in 1986. Email address: drrobertlees@ gmail.com. 
Baker \& Lees

\section{Literature Review}

\section{Prevalence of Parents and Children with Mental Health Concerns}

Studies show an increased rate of psychiatric disorders in young people whose parents experience mental health concerns $\left(\mathrm{MHC}^{1}\right)$ as compared to children whose parents are not impacted by mental illness. Beardslee, Versage, and Galdstone (1998) maintain that "children of adults with affective illness are substantially more vulnerable to the development of psychopathology in general, and depression specifically, than are the children of non-ill adults" (p. 1137). In Australia between $25 \%$ to $50 \%$ of children and youth with parents who have MHC also experience psychological disorders (Falkov, 2009b). In a recent meta-analysis, Siegenthaler, Munder, and Egger (2012) highlighted the presence of mental disorders in children that were similar to those of their parents. Studies have also explored the differences in the impact of maternal and paternal MHC on sons and daughters and have found that sons of fathers with a mental illness are at an increased risk of developing a range of difficulties as compared to girls (Ramchandani \& Psychogiou, 2009). Besides increasing the possibility of their children developing MHC the presence of MHC in parents can impact offspring in other adverse ways as well. Bassani, Padoin, Philipp, and Veldhuizen (2009) note in their Canadian study that while parental MHC convey a risk to children they may also present exposure to conditions such as trauma, high-risk neighborhoods, downward social mobility and poor social and economic support all of which also increase risk. Furthermore, according to Reupert and Mayberry (2009b), both men and women who have MHC are at an increased risk of losing responsibility for their children's care.

\footnotetext{
${ }^{1}$ For the purposes of this paper the definition of mental health concerns (MHC) is used to refer to mental health disorders, psychiatric illness, etc.; MHC is considered by the authors to be a less problematic definition.
} 
Although the connection between parental mental illness and adverse outcomes for children has been established by research, there is a lack of information around the proportion of adults dealing with mental illness who are parents, as well as a lack of information about the percentage of parents experiencing MHC whose children are accessing mental health services (Falkov, 2009b). Vidair et al. (2011) elaborated on this deficiency in research by pointing out that "few studies assessing the relationship between parent and child psychopathology have specifically targeted families in which either the parent or child is experiencing current psychiatric symptoms for which they are seeking treatment" (p. 2).

Although there is a need for more studies that explore this dynamic, there are some that have investigated the percentages of adults with MHC who are parents and others that have explored the number of children who live with parents who have MHC. In a reanalysis of the National Comorbidity Survey in the USA, Nicholson, Biebel, Williams, and Katz-Leavy (2004) discovered that $68 \%$ of women with disorders were mothers and $57 \%$ of men with disorders were fathers. An Australian study by Hearle, Plant, Jenner, Barkla, and McGrath (1999) found that $59 \%$ of women in contact with Community Mental Health Services were mothers. In a Canadian study by Bassani, Padoin, Philipp, and Veldhuizen (2009) it was discovered that one in every ten children less than 12 years of age live with a parent who has some form of a psychiatric disorder.

The inverse question of how many parents of children who are receiving mental health services have their own MHC has started to be addressed in literature as well. Vidair et al. (2011) explored the prevalence of symptoms in parents who brought their children to a child and adolescent psychiatric evaluation service and found that a significant percentage of parents seeking treatment for their children were suffering from depressive and anxious symptoms. In 
fact, $19 \%$ and $17 \%$ of mothers and $23 \%$ and $20 \%$ of fathers endorsed elevated depression and anxiety symptoms respectively (2011). Another study by Swartz et al. (2005) also investigated the proportion of parents whose children were accessing mental health services and who had MHC; it was found that $61 \%$ of the 222 mothers who brought their children for evaluation at a child mental health clinic were experiencing a mental health disorder, most commonly depression and anxiety. Another study by Kilmer, Cook, and Munsell (2010) of families participating in Systems of Care initiatives across 28 sites revealed that $71 \%$ of the youth had a biological parent with major depression. A survey of clinicians by N. Mercer (personal communication, January, 4, 2010) found that a children's mental health team that carefully reviewed its client list identified $68 \%$ of the parents as having diagnosed or suspected MHC.

The noteworthy figures in these findings demonstrate the urgent need for further exploration of the mental health status of all family members when individuals seek mental health services as the health of one member can intricately impact the health of others in the family. As articulated by Folkov,

The family plays a central role in the individual's experience of mental illness and mental illness has a critical influence on family life. ... Family is about mental illness and social care, parenting and mental illness, children and adults, support and protection (Falkov, 2009a, p. 7).

\section{Family Centered, Integrative Care}

Falkov outlined four ways that the mental health and wellbeing of children and their parents who have MHC are connected, which include: parental mental illness can adversely affect the development and sometimes the safety of children; growing up with a parent who has mental illness can negatively influence transition to and adjustment in adulthood; children, especially those with emotional, behavioral, or physical problems, can precipitate or exacerbate mental health concerns in their parents; and adverse circumstances can negatively impact both 
Parental Mental Illness and Coping

child and caregiver mental health (Falkov, 2009a). Falkov emphasized that although this relationship between symptoms, behavior, parenting responsibilities, and the quality of relationships is well known, it has proven challenging to integrate such knowledge into skill development of mental health practitioners. Siegenthaler, Munder, and Egger (2012) demonstrated that family interventions can decrease the risk of children developing the same mental illness as a parent by $40 \%$; a lack of this approach in practice obstructs the potential benefits it may provide for all family members. In fact, Kilmer et al. (2010) echoed the growing concern caregivers, advocates, and researchers have that "the failure to address other family needs can impede the long-term recovery of the 'identified' client and lead to potential negative consequences for siblings and others in the family" (p. 335). While discussing the Systems of Care philosophy and the wraparound approach, where services and supports are ideally supposed to address the needs of the whole family, Kilmer et al. further elaborated on this tension between research and practice in working with families who deal with MHC by stating that "overall, growing evidence suggests that, despite a strong conceptual emphasis on family-centered systems, the broader needs of family are frequently neither discussed nor incorporated into plans of care" (p. 334).

This lack of family-centered, integrated care in the face of the evidence ascribing its benefit has led researchers to propose changes. Vidair et al. (2011) suggested the development of "mental health systems that will be able to provide assessments and deliver evidence-based treatments to children, mothers, and fathers within the same clinical setting” (p. 9). Reiss (2011) recommended that professionals consider two levels of integration of child and adult mental health services by considering the parent-child dyad as both the unit of assessment and the unit of treatment: 
If we find that a child has a psychiatric disorder, it should be standard practice to assess the mental health of each parent. The same is true for adult psychiatric patients who are parents: we need to collaborate with them to assess their children . . child and adult clinicians would plan an integrated treatment plan with the family to jointly monitor the forward progress of treatment, evaluate its outcome, and plan for appropriate follow-up to avoid relapse in the child and parent (p. 432).

The research evidence above suggests that large numbers of parents bringing their children for mental health treatment have their own MHC to address. We were aware of limited study of this phenomenon in the Canadian context. As well we wondered how aware clinicians are of parental MHC in the families they see. Given the gap between the need for mental health services and the availability of mental health services, we wondered what supports parents would identify for their self-care, what barriers they perceived, and what they wished was in place to help them cope.

\section{Method}

\section{Clinician and Caregiver Interviews}

A survey of the prevalence of MHC among parents whose children were currently accessing services from a mental health outpatient center was conducted by interviewing the children's clinicians. Our purpose was to gain an understanding of the clinicians' perception of parental mental health and then to check this with the parents' self-report. A contact list of parents who had diagnosed or suspected MHC according to the clinicians' perceptions was then created to inform the next step: interviewing the parents by phone. The purpose of the phone interviews was to hear from the participants directly about their mental health coping, what helps and hinders their coping, and what they wish they had to help them cope. 
Parental Mental Illness and Coping

\section{Procedure}

All 78 cases currently receiving services at the child and youth outpatient center were reviewed. The following questions were among those asked of each clinician: (a) does the parent have MHC (diagnosed/suspected), and (b) what type of concern (e.g., anxiety, depression, bipolar, schizophrenia, etc.) does the parent or caregiver have? Clinician interviews revealed that 55 of the 78 families had at least one parent who had a diagnosed or suspected MHC. A list was made of these parents and was given to three phone interviewers who made at least one attempt to contact all 55 homes. A convenience sample of 28 parents who were successfully contacted participated in and completed the interview.

\section{Measures}

An interview guide was designed for each interview with the parents. Participants were asked what helps them cope, what hinders them from coping well, and what they wish was there to help. Data was collected through telephone interviews and was sorted by two of the telephone interviewers into helping, hindering, and wish list comment. The authors then conducted data analysis by recognizing themes and forming categories from the relevant comments noted. Categories were then given operational definitions and self-descriptive titles to portray the voices of parents and caregivers.

Participants were first asked if they or another parent had ever dealt with MHC and if so were then were asked to tell a little bit about that experience. If they denied any MHC, they were asked to describe some of the other types of stresses they deal with as a parent. As participants replied to each question, their answers were hand-written into an interview guide that helped to indicate relevant comments regarding helpful factors, hindering factors, and wish list items. Prompts were used for each step of the interview. 
For helpful factors, the participants were asked, "As a parent, what has helped you cope [with your MHC]. For example, did you get assistance from a doctor, a psychiatrist, medication, a mental health worker/counsellor/addiction worker, a friend, church, or support groups?" For hindering factors, participants were asked, "What have been some of the specific challenges you've faced in coping?" If needed, the question "What kinds of things have made it harder for you to do well?" was used as a probe. For the wish list, participants were prompted with the question, "Are there other things that would help you to continue to cope such as such as groups that deal with either the issues you face or helping your child, access to counselling for mental health or addiction, telephone or internet support, medication, funding for medication, or anything else?" If needed, the questions "I wonder what else might be helpful to you that you haven't had access to" and "What do you wish would be, or had been, there to help you?" were used.

Finally, interviewers indicated post-interview whether the participants' response to the question of the existence of $\mathrm{MHC}$ in the home was in accordance with the report from their child's clinician. Parents were also asked if they would like to receive an email list of online and community resources. A list of those resources was sent to each of the families that indicated that they would like to receive one.

\section{Results}

\section{Participants}

Of the participants contacted, 26 were female and 2 were male. Eighteen of the 28 provided information about $\mathrm{MHC}$ in the home that was in accordance with the information gathered in the clinician interviews. Six of the 28 did not indicate MHC whereas the clinician interviewed did so. Three of the 28 indicated MHC although the clinician interviewed was 
Parental Mental Illness and Coping

uncertain. One of the 28 telephone interviewees did not indicate whether there were MHC that were in agreement with the clinician interview. Three of the 28 parents said they did not wish to receive a list of online and community services; however, the remaining 25 did want a list, and they provided either an email or a mailing address.

\section{Emerging Categories from Parent Interviews}

There were 218 relevant comments gathered from parent interviews: 91 helpful items, 71 hindering items, and 56 wish list items. Themes were noted and incidents were organized into categories.

Helpful items. The following helpful categories were mentioned by five or more participants: family, friend, and social support; a counsellor, mental health worker, psychologist, or social worker; a medical doctor/physician; medication; self-improvement/determination; a supportive partner/spouse; inspiration/faith; and specific programs/support groups. Other helpful things mentioned included: decrease in stress as kids grow up and mature; having appointments available after school; leaving a bad relationship; and being active in community.

Hindering items. The following hindering categories were mentioned by five or more participants: lack of finances; stress of everyday life; lack of support; lack of time; lack of services/resources and access to them; parenting stresses and/or stress of special needs child; and difficulties of parental MHC. Other hindrances mentioned included: getting mixed up with the wrong people, stigma, feeling judged by a social worker, kids going through same issues triggering memories, not knowing where to turn initially, or waiting to deal with MHC.

Wish list items. The following wish list categories were mentioned by five or more participants: more support groups for specific issues; financial assistance; access to or ongoing counselling; general help/support network; and more services/better access. Other wishes 
mentioned included more access to education/information to lessen labelling, housing and job options, and greater awareness for kids of resources (e.g., more advertising at schools).

Table 1: Emerging categories, number of items that support it, and examples. $n=28$

\begin{tabular}{|c|c|}
\hline Helpful Categories & Examples of Relevant Comments \\
\hline Family, Friend and Social Support $(\mathbf{1 2}, \mathbf{4 3 \%})$ & $\begin{array}{l}\text { "They are there to talk to. The steam doesn't } \\
\text { get built up and the top doesn't blow at the } \\
\text { wrong moment." }\end{array}$ \\
\hline $\begin{array}{l}\text { Counsellor/MH Worker/Psychologist } \\
(\mathbf{1 7}, \mathbf{6 1 \%})\end{array}$ & $\begin{array}{l}\text { "Helped me realize my need to work on self- } \\
\text { esteem and boundary issues." }\end{array}$ \\
\hline Physician $(10,36 \%)$ & $\begin{array}{l}\text { "He sits down and talks about action plans and } \\
\text { short term goals." }\end{array}$ \\
\hline Medication $(\mathbf{1 3}, \mathbf{4 6 \%})$ & $\begin{array}{l}\text { "Before I was on medication I had no } \\
\text { motivation. I was neglected and didn't want to } \\
\text { get out of bed. Now I actually take time for } \\
\text { me." }\end{array}$ \\
\hline $\begin{array}{l}\text { Self-Improvement/Determination } \\
(\mathbf{1 2}, \mathbf{4 3 \%}) \\
\text { (hobby, walks, time in nature, diet, using } \\
\text { breathing techniques, exercise) }\end{array}$ & "Going for a walk relieves stress." \\
\hline Supportive Partner/Spouse $(\mathbf{5 , 1 8 \%})$ & $\begin{array}{l}\text { "He made more 'me time' to get out and go to } \\
\text { exercise class." }\end{array}$ \\
\hline $\begin{array}{l}\text { Inspiration/Faith }(\mathbf{8}, \mathbf{2 9 \%}) \\
\text { (Church support, prayer, relationship with } \\
\text { their child, knowing things will get better) }\end{array}$ & $\begin{array}{l}\text { "Gives optimism and perspective, changes my } \\
\text { attitude to positive." }\end{array}$ \\
\hline $\begin{array}{l}\text { Specific Programs and/or Support Groups (6, } \\
\mathbf{2 1 \% )}\end{array}$ & $\begin{array}{l}\text { "Finding out that you're not the only parent } \\
\text { and learning how other parents cope." }\end{array}$ \\
\hline Hindering Categories & Examples Relevant Comments \\
\hline Lack of Finances $(\mathbf{8}, \mathbf{2 9 \%})$ & "I can't afford things for my children to do" \\
\hline $\begin{array}{l}\text { Stress of Everyday Life } \mathbf{( 1 4 , 5 0 \% )} \\
\text { (relocation, break-ups, health issues, fatigue, } \\
\text { laundry, housework, school, working) }\end{array}$ & $\begin{array}{l}\text { "Normally I can cope, but add one more thing } \\
\text { and it all crumbles down." }\end{array}$ \\
\hline Lack of Support $(\mathbf{1 1}, \mathbf{3 9 \%})$ & $\begin{array}{l}\text { "I do it alone. I'm a single parent and have no } \\
\text { one to turn to and that makes it very difficult . } \\
\text {. . it would be nice to have someone to talk to } \\
\text { that might understand." }\end{array}$ \\
\hline
\end{tabular}


Table 1, cont.

\begin{tabular}{|c|c|}
\hline Lack of Time $(6,21 \%)$ & $\begin{array}{l}\text { "In a house with so many things going on at } \\
\text { once it's a big challenge finding time to let go } \\
\text { and give to yourself." }\end{array}$ \\
\hline $\begin{array}{l}\text { Lack of Services/Resources and Access to } \\
\text { Them }(\mathbf{6}, \mathbf{2 1 \%} \text { ) } \\
\text { (wait times, assessments, paperwork, } \\
\text { bureaucracy) }\end{array}$ & $\begin{array}{l}\text { "It's frustrating how many steps there are } \\
\text { before receiving help." }\end{array}$ \\
\hline $\begin{array}{l}\text { Parenting Stress and/or Stress of Special Needs } \\
\text { Child }(\mathbf{1 2}, \mathbf{4 3 \%})\end{array}$ & $\begin{array}{l}\text { "When a child has an opinion or judgment it } \\
\text { becomes tiring . . . . it heightens my anxiety } \\
\text { when they engage in conflict." }\end{array}$ \\
\hline $\begin{array}{l}\text { Difficulties related to MHC }(\mathbf{8}, \mathbf{2 9 \%}) \\
\text { (hospitalization, being house-bound, issues } \\
\text { with medication) }\end{array}$ & $\begin{array}{l}\text { "I didn't like my meds .... p pills put me to } \\
\text { sleep." }\end{array}$ \\
\hline Wish List Categories & Examples of Relevant Comments \\
\hline $\begin{array}{l}\text { More Support Groups for Specific Issues (7, } \\
\mathbf{2 5 \% )}\end{array}$ & $\begin{array}{l}\text { "A group for families dealing with mental } \\
\text { health issues .... knowing I'm not alone, } \\
\text { sharing the load." }\end{array}$ \\
\hline $\begin{array}{l}\text { Financial Assistance }(\mathbf{8}, \mathbf{2 9} \%) \\
\text { (medication, transportation, food vouchers, } \\
\text { help with child care) }\end{array}$ & "Food vouchers .... . so we can eat." \\
\hline Access to or Ongoing Counselling $(\mathbf{1 1}, \mathbf{3 9 \%})$ & $\begin{array}{l}\text { "Counselling for the whole family, talking to } \\
\text { other people that have gone through similar } \\
\text { situations." }\end{array}$ \\
\hline $\begin{array}{l}\text { General Help/Support Network }(\mathbf{6}, \mathbf{2 1 \%}) \\
\text { (child care, housework, transportation) }\end{array}$ & $\begin{array}{l}\text { "I don't have family members here .... help } \\
\text { with housework, child care, maybe some } \\
\text { medical help." }\end{array}$ \\
\hline $\begin{array}{l}\text { More Services/Better Access } \mathbf{( 2 1 , 7 5 \% )} \\
\text { (less wait times, telephone/internet support, } \\
\text { residential treatment center for youth, } \\
\text { parenting classes, resources while on wait list, } \\
\text { dual diagnosis treatment, local teen center, } \\
\text { school support, assistance while trialing meds, } \\
\text { person to talk to versus answering machine, } \\
\text { more counsellors on staff, resources while on } \\
\text { wait list) }\end{array}$ & $\begin{array}{l}\text { "More staff so counsellors can be available } \\
\text { more . . . . sometimes it's difficult to get } \\
\text { through to a counsellor in emergencies." }\end{array}$ \\
\hline
\end{tabular}


Baker \& Lees

\section{Discussion}

Findings

Results closely mimicked those found in a survey on another Canadian child and youth mental health clinic (Mercer, N., January 4, 2010), in which clinicians were asked their perception of the mental health of the parents of their young clients. Clinicians in our survey identified $71 \%$ of their clients' parents as having known or suspected MHC. In Mercer's project, it was $68 \%$. Our results also resemble those of Schwarz et. al (2005) who found $61 \%$ of 222 mothers bringing children for treatment had MHC.

Depression was the most common specific mental health concern attributed to parents, with $38 \%$ of parents identifying it as a concern, followed by anxiety, with $26 \%$ identifying it as a concern. Eighteen percent of parents reported experiencing both anxiety and depression. When taken together, these two MHC accounted for about two-thirds of the concerns. When we contacted the participants, we found the clinicians' insights about MHC were correct $75 \%$ of the time.

When we asked participants what helped them cope, comments related to mental health service indicated that parents drew on a wide range of options including counsellors, physicians, medication, and support groups. Hindering items related to the mental health system noted problems with access to services and the stress of raising a child with special needs. These participants wished there were more services and supports available across professional and community domains, including access to counselling for them. 
Parental Mental Illness and Coping

\section{Limitations}

The interviews in this survey were not audio recorded, limiting opportunities for review. A convenience sample was used for the coping methods portion of the study, and thus this could be a misrepresentation of the overall population of parents bringing children for treatment.

\section{Implications for Practice}

In speaking to the absence of information on the identification of parents with MHC and the particular difficulties they face, Falkov (2009b) stressed that this gap causes a significant barrier to progress and made the appeal that all services have a part to play in identifying families that deal with parental mental illness. The findings of this study support the practice of screening family members for mental health disorders and assessing their level of coping. This could allow the clinician to make recommendations for the family members' own self-care as one part of providing support to the children in the family. Vidair et al. (2011) particularly emphasized the value of screening all parents for anxiety and depression when the children are being evaluated for MHC as it would provide an opportunity to discuss the relationship between parents' mental health symptoms and child treatment outcomes and to address the treatment needs of all family members. Reupert, Mayber, and Kawalenko (2012) also identify children’s mental health services as an approporiate location for identifying the mental health status of parents and providing holistic intervention. This survey substantiate the emphasis on a greater family focus in treatment so that parents can benefit, particularly when dealing with anxiety and depression - disorders for which child mental health clinics have relative treatment strength and success.

Our findings, along with conclusions from other studies, also identify the need for family-focused training for clinicians working with children and youth. Bannerman and Falkov 
(2009) discussed the lack of emphasis placed on the mental health needs of parents and carers despite staff being in contact with them while working with their children and highlighted the importance of a training program that will "support staff of varying experience, with differing professional backgrounds, working in diverse settings, and within a context of insufficient resources and stigma regarding mental illness" (p. 80). Reupert and Mayberry (2009), in their recent exploration of Australian programs to support children and adolescents whose parents have a mental illness, concluded that "program facilitators need training, funding and organizational supports in designing and identifying appropriate evaluation measures, which meet the needs of various stakeholders" (p.131). After recounting her personal experience as a mother with a mental illness, Fox (2009) highlighted the lack of ability clinicians often feel in working with families despite the clinicians' acknowledgment of the importance of a family approach and argued that,

Clearly our training programs need to do a better job of preparing new clinicians to see and understand the value of working with families as well as the importance of the parenting role for people with a mental illness, then teach them to do family work. (p. 151)

Beardslee et al. (1998) listed parenting problems and chronicity/severity of family illness amongst risk factors that contribute to an increased rate of mental health disorders in children. Our findings are in agreement with this and demonstrate a need to establish programs aimed at developing mental health coping skills for the whole family. The voices of parents in our survey cry out for change through wish list items that are in close accordance with the following recommendations for policy as outlined by Kilmer et al. (2010): 1) changes that would orient mental health systems to support and to strengthen families rather than to focus more narrowly on the needs of identified children; 2) local implementation that focuses more on how to deliver needed services and supports to the family through specific practices such as identifying needs 
Parental Mental Illness and Coping

and strengths of the whole family; 3) the provision of peer-to-peer family support models in which families who have navigated the system provide support for families; and 4) a modification of funding mechanisms to help put a family focus into action.

\section{Conclusion}

Our findings support those reported by Reiss (2011) of the high correspondence between children's mental health needs and those of their parents. As well, they suggest that clinicians have accurate awareness of the cases where parents of the children they are treating have MHC. Although the majority of parents reported receiving helpful services, the majority also indicated the need for more services and greater access to counselling, support groups, and support networks. These requests are in accordance with those of parents in a small study by Reupert and Mayberry (2009b), where fathers with a MHC expressed the need for family-focused intervention that is geared toward educating family members, including children, about mental illness.

The findings of our survey can be added to the voices calling for expansion beyond silos in the mental health service working from the medical model to one that works with whole families, assuming the often trans-generational nature of mental illness and the benefits of ecological models of practice. Innovations like the workforce training materials found on the COPMI website (http://www.copmi.net.au) and the Australian Family Focused Intervention are interventions that reflect such an approach. This need for development of a family-focused, multidisciplinary and cross-sectional approach is also expressed by Cowling and McGorry (2012) who assert that,

researchers and practitioners, informed by consumer and carer involvement, share continuing responsibility for developing evidence that informs and shapes effective policy and program changes at all level and in all sectors to prevent 
Baker \& Lees

mental illness and promote mental health for all members of families when a parent has a mental illness (p.5).

The importance of a thorough assessment framework when a child or parent is referred to service is substantiated by our findings, and they support the hope offered by Heriot (2009) when she asserts that "risk need not determine destiny. . . . [with] a broad assessment model that includes and involves all relevant individual, family and other systemic factors, management and therapeutic outcomes may be optimized even with difficult or complex situations" (p. 93). Our survey ultimately lends support to the notion that family focused mental health coping is an appropriate focus for training and practice in the mental health field. 
Parental Mental Illness and Coping

\section{References}

Bannerman, N., \& Falkov, A. (2009). Conceptual models-Part 2: A family approach. The Clinician, 4, 80-84.

Bassani, D. G., Padoin, C. V., Philipp, D., \& Veldhuizen, S. (2009). Estimating the number of children exposed to parental psychiatric disorders through a national health survey. Child and Adolescent Psychiatry and Mental Health, 3: 6. Published online 2009 February 19. doi: 10.1186/1753-2000-3-6.

Beardslee, W. R., Versage, E. M., \& Gladstone, T. R. G. (1998). Children of affectively ill parents: A review of the past 10 years. Journal of the American Academy of Child \& Adolescent Psychiatry, 37, 1134-1141. doi:10.1097/00004583-199811000-00012

Cowling, V., \& McGorry, P. D. (2012). Parental mental illness is a family matter. Medical Journal of Australia, open 1(Suppl 1), 5. doi:10.5694/mjao12.10553

Falkov, A. (2009). Children of parents experiencing mental illness. The Clinician, 4, 7-11.

Falkov, A. (2009b). Impacts and influences: The scope and relevance of mental illness in a parent or carer for dependent children. The Clinician, 4, 44-47.

Fox, M. B. (2009). Second chance at motherhood. Psychiatric Rehabilitation Journal, 33, 150152. doi:10.2975/33.2.2009.150.152

Hearle, J., Plant, K., Jenner, L., Barkla, J., \& McGrath, J. (1999). A survey of contact with offspring and assistance with child care among parents with psychotic disorders. Psychiatric Services, 50, 1354-1356.

Heriot, S. (2009). Assessment of need. The Clinician, 4, 90-93. 
Baker \& Lees

Kilmer, R. P., Cook, J. R., \& Munsell, E. P. (2010). Moving from principles to practice: Recommended policy changes to promote family centered care. American Journal of Community Psychology, 46, 332-341. doi:10.1007/s10464-010-9350-9

Nicholson, J., Biebel, K., Williams, V.F., \& Katz-Leavy, J. (2004) Prevalence of Parenthood in Adults with Mental Illness: Implications for State and Federal Policy, Programs, and Providers. In Center for Mental Health Services. Mental Health, United States, 2002. Manderscheid, R.W., \& Henderson, M.J., (Eds.). DDHS Pub No. (SMA) 3938. Rockville, Maryland: Substance Abuse and Mental Health Services Administration, pp.120-137.

Ramchandani, P., \& Psychogiou, L. (2009). (2009). Paternal psychiatric disorder and children's psychological development. The Lancet Psychiarty, 374, 646-653. doi:10.1016/S01406736(09)60238-5.

Reiss, D. (2011). Parents and children: Linked by psychopathology but not by clinical care. Journal of the American Academy of Child \& Adolescent Psychiatry, 50, 431-433. doi:10.106/j.jaac.2011.02.2005

Reupert, A. E., Maybery, D. J. (2009). A "snapshot" of Australian programs to support children and adolescents whose parents have a mental illness, Psychiatric Rehabilitation Journal, 33, 125-132. doi:10.2975/33.2.2009.125.132

Reupert, A. E., Maybery, D. J. (2009b). Fathers' experience of parenting with a mental illness. Families in Society: The Journal of Contemporary Social Services, 90, 61-68. doi:10.1616/1044-3894.3846

Reupert, A. E., Maybery, D. J., Kowalenko, N. M. (2012). Children whose parents have a mental illness: prevalence, need and treatment. Medical Journal of Australia, open 1(Suppl 1), 7-9. doi:10.5694/mjao11.11200 
Siegenthaler, E., Munder, T., \& Egger, M. (2012). Effect of preventive interventions in mentally ill parents on the mental health of the offspring: Systematic review and meta-analysis. Journal of the American Academy of Child and Adolescent Psychiatry, 51, 8-17. doi: 10.1016/j.jaac.2011.10.018

Swartz, H. A., Shear, M. K., Wren, F. J., Greeno, C. G., Sales, E., Sullivan, B. K., \& Ludewig, D. P. (2005). Depression and anxiety among mothers who bring their children to a pediatric mental health clinic. Psychiatric Services, 56, 1077-1083. doi:10.1176/appi.ps.56.9.1077

Vidair, H. B., Reyes, J. A., Shen, S., Parrilla-Escobar, M. A., Heleniak, C. M., Hollin, I. L., . . Rynn, M. A. (2011). Screening parents during child evaluations: Exploring parent and child psychopathology in the same clinic. Journal of the American Academy of Child \& Adolescent Psychiatry, 50 (5), 441-450. doi:10.1016/j.jaac.2011.02.002 